\title{
TERRITORIALIDADE, IDENTIDADE E CULTURA DA COMUNIDADE REMANSCENTE QUILOMBOLA ILHA DE SÃO VICENTE/TOCANTINS
}

Cristina de Sousa Fonseca Almeida ${ }^{1}$ Luís Fernando da Silva Laroque ${ }^{2}$

Resumo: O estudo objetiva compreender o processo de ocupação territorial, os impasses e as conquistas pela comunidade quilombola llha de São Vicente/Tocantins. A metodologia utilizada foi qualitativa, composta de revisão bibliográfica, análise documental e pesquisa de campo com elaboração de diários e aplicação de entrevistas. O estudo constatou que essa comunidade possui intensa relação com o território dos antepassados e com a reprodução dos seus traços culturais. Observou-se ainda que por meio das lutas e com base na legislação brasileira e da dívida histórica com os escravizados, impasses foram transpostos e reconhecido o direito a esse território, situação que colaborou para revitalização da sua identidade e cidadania como remanescente quilombola da Ilha São Vicente.

Palavras Chaves: Remanescente Quilombola. Ilha de São Vicente. Território, comunidade.

\section{TERRITORIALITY, IDENTITY AND CULTURE OF THE REMANSCENT QUILOMBOLA COMMUNITY IN THE ISLAND OF SÃO VICENTE IN THE STATE OF TOCANTINS}

Abstract: The objective of this study is to understand the process of territorial occupation, impasses and conquests by the Quilombola community of the Island of São Vicente in the state of Tocantins. A qualitative methodology, composed of bibliographical review, documentary analysis and field research, with annotations and interviews, was used. It was found that this community has an intense relationship with the ancestors' territory and with the reproduction of their cultural traits. After manifestations, based on the rights on the Brazilian legislation, and also the historical debt to the enslaved, impasses were transposed. So, the right to the territory was, then, recognized. This contributed to the revitalization of the identity and citizenship for the remaining Quilombola of São Vicente.

Keywords: Remaining Quilombola. Island of São Vicente. Territory. Community.

\section{TERRITORIALIDAD, IDENTIDAD Y CULTURA DE LA COMUNIDAD REMANENTE "QUILOMBOLA" ISLA DE SÃO VICENTE / TOCANTINS}

Resumen: El estudio tiene como objetivo comprender el proceso de ocupación territorial, los impasses y las conquistas de la comunidad "quilombola" Isla de São Vicente / Tocantins. La metodología utilizada fue cualitativa, compuesta de revisión bibliográfica, análisis documental e investigación de campo con elaboración de diarios y aplicación de entrevistas. El estudio constató que esa comunidad tiene

\footnotetext{
1 Instituto Federal de Educação, Ciência e Tecnologia do Tocantins - IFTO, Tocantins, Brasil. E-mail: crisfonseka@ifto.edu.br, https://orcid.org/0000-0001-9114-2650

2 Universidade do Vale do Taquari - Univates, Centro de Ciências Humanas e Sociais, Lajeado, Rio Grande do Sul, Brasil. E-mail: Iflaroque@univates.br, https://orcid.org/0000-0003-1861-4679
} 
intensa relación con el territorio de los antepasados y con la reproducción de sus rasgos culturales. Se observó, además, que por medio de las luchas y con base en la legislación brasileña y de la deuda histórica con los esclavizados, impases fueron transpuestos y reconocido el derecho a ese territorio, situación que colaboró para revitalización de su identidad y ciudadanía como remanente "quilombola" en la Isla São Vicente.

Palabras Claves: Remanente "Quilombola". Isla de San Vicente. Territorio, comunidad.

\section{Introdução}

O estudo trata da Comunidade Remanescente de Quilombo ${ }^{3}$ Ilha de São Vicente, localizada no extremo norte do estado do Tocantins, fronteira com o Pará; surge a partir da participação, como membro, do Núcleo de Estudos Afro-brasileiros e Indígenas (NEABI), do Instituto Federal de Educação Ciência e Tecnologia do Tocantins (IFTO), no Campus Araguatins.

Percebeu-se, por meio da participação nesse núcleo de pesquisa, que há poucas informações sobre essa e outras comunidades quilombolas, especialmente diante da riqueza cultural e histórica, das lutas e impasses por que passaram tais comunidades, desde a sua formação. Sobre a comunidade da Ilha de São Vicente, há ainda menos registros, já que o próprio grupo apenas tenha se reconhecido como remanescente de quilombos recentemente. Para além disto, também justifica a relevância da temática, o fato de que a Constituição Federal de 1988 reconheceu as populações quilombolas como sujeitos de direitos, inclusive quanto ao território em que tradicionalmente desenvolvem seu modo de vida.

Assim, o estudo tem o objetivo de compreender o processo de ocupação territorial, os impasses e as conquistas pela comunidade quilombola llha de São Vicente/Tocantins. Do ponto de vista metodológico tratou-se de uma pesquisa qualitativa, composta de levantamento e análise bibliográfica e documental, bem como pesquisa de campo e observação "in loco", promovida junto à comunidade quilombola Ilha de São Vicente.

Na revisão bibliográfica e pesquisa documental, vale salientar que o livro de Leônidas G. Duarte "De São Vicente a Araguatins" (1970) e o laudo elaborado por Rita D. Lopes "Relatório Antropológico da Comunidade Quilombola Ilha São Vicente" (2014), revelam as origens dessa comunidade quilombola, sua historicidade e ainda

\footnotetext{
${ }^{3}$ Comunidades remanescentes de quilombos - nomenclatura usada pela Constituição da República Federativa do Brasil de 1988, no ADCT no Art. 68, para designar a população negra que vive nos quilombos contemporâneos. Nesta Dissertação de Mestrado será utilizado como sinônimo de comunidade quilombola (BRASIL, Constituição de 1988).
} 
aspectos culturais e sociais da mesma. Neste sentido, a pesquisa buscou sistematizar e ampliar as informações que essas obras apresentavam, especialmente no que diz respeito ao protagonismo negro e a questões étnicoraciais no contexto brasileiro de resistência; não mais naquela perspectiva errônea de fraqueza, resignação e aceitação da escravidão, conforme foi difundido por uma produção científica mais tradicional.

Sendo assim, acredita-se que uma pesquisa como essa permite uma revisão da literatura, com um olhar ainda mais crítico, o que, por sua vez, gera material que servirá como fonte de pesquisa não apenas para as comunidades do entorno, como também para as próprias instituições de ensino da região, e até de fora, especialmente com a alteração da Lei Federal 9.394/96, pela Lei № 11.645/20084 que acrescentou o artigo 26-A, determinando-se como obrigatória a inclusão do ensino sobre História e Cultura Afro-Brasileira e Indígena, nos Ensinos Fundamental e Médio.

Ademais, no que diz respeito à apropriação do território da llha de São Vicente, tanto pela comunidade remanescente de quilombo, quanto pela população não-quilombola e seus conflitos; optou-se por uma análise documental, sempre que possível; pelas referências bibliográficas e ainda por uma pesquisa etnográfica, "utilizada tradicionalmente para a descrição dos elementos de uma cultura específica, tais como comportamentos, crenças e valores, baseada em informações coletadas mediante trabalho de campo" (GIL, 2010, p.40); além da análise descritiva, que "procura especificar as propriedades, as características e os perfis importantes de pessoas, grupos, comunidades ou qualquer outro fenômeno que se submeta à análise" (SAMPIERI; COLLADO; LUCIO, 2006, p.101).

\footnotetext{
${ }^{4}$ Art. $1^{\circ} \mathrm{O}$ art. 26-A da Lei $\mathrm{n}^{\circ} 9.394$, de 20 de dezembro de 1996, passa a vigorar com a seguinte redação:

"Art. 26-A. Nos estabelecimentos de ensino fundamental e de ensino médio, públicos e privados, torna-se obrigatório o estudo da história e cultura afro-brasileira e indígena.

$\S 1$ ㅇ O conteúdo programático a que se refere este artigo incluirá diversos aspectos da história e da cultura que caracterizam a formação da população brasileira, a partir desses dois grupos étnicos, tais como o estudo da história da África e dos africanos, a luta dos negros e dos povos indígenas no Brasil, a cultura negra e indígena brasileira e o negro e o índio na formação da sociedade nacional, resgatando as suas contribuições nas áreas social, econômica e política, pertinentes à história do Brasil.

§ 2o Os conteúdos referentes à história e cultura afro-brasileira e dos povos indígenas brasileiros serão ministrados no âmbito de todo o currículo escolar, em especial nas áreas de educação artística e de literatura e história brasileiras" (BRASIL. Lei no 11.645, de 10 março de 2008, texto digital).
} 
A intenção foi de conhecer as relações étnico-raciais e culturais da comunidade em estudo, tendo em vista, também, sua relação com o território, para o que se utilizou a análise documental, e, com os moradores da comunidade, as entrevistas semiestruturadas, que são "um procedimento utilizado na investigação social, para a coleta de dados ou para ajudar no diagnóstico no tratamento de um problema social"(LAKATOS; MARCONI, 2010, p.178); além de registros de diários de campo, registro fotográfico e observação "in loco" do cotidiano dessa comunidade.

Nas entrevistas semiestruturadas, tem-se um roteiro prévio, ao qual se acrescentam perguntas, à medida que se obtém os dados na própria entrevista. Daí, a importância de se proceder anteriormente à leitura de bibliografia disponível sobre o tema, para se construir esses primeiros questionamentos que formam o eixo central da entrevista com os interlocutores. Vale salientar que nos fragmentos das entrevistas degravadas utilizadas para este estudo, fez-se a opção de respeitar no texto, a expressão original da fala dos sujeitos.

Além disso, também foi importante analisar os documentos que não apenas comprovam os conflitos, bem como a posse da terra por parte da comunidade remanescente de quilombos; tudo isso em um enfoque dialético, já que se trata de um método que "fornece as bases para uma interpretação dinâmica e totalizante da realidade e que estabelece que os fatos sociais não podem ser entendidos quando considerados isoladamente, abstraídos de suas influências políticas, econômicas, culturais etc" (GIL, 2010, p.14).

Assim, a pesquisa tendo como base teórica autores que tratam da cultura, da territorialidade, da identidade e da memória, buscou-se compreender no processo histórico, questões envolvendo a territorialidade e a identidade da comunidade remanescente de quilombos da Ilha de São Vicente, bem como as configurações sociais e traços culturais, que asseguram a sobrevivência e o modo de vida do grupo, individual e coletivamente.

\section{A questão negra no Brasil e em Tocantins}

De acordo com Mattoso (1982) e Fausto (2015), os africanos foram trazidos da Guiné e da Costa da Mina no séc. XVI e do Congo e de Angola no XVII. Calcula Gomes (2013), ainda, que cerca de 10 milhões de pessoas tenham sido 
"arrancados" de sua localidade com fins de escravidão, sendo que pelo menos $40 \%$ (quarenta por cento) desse total foi trazido para o Brasil.

Nesse sentido, cabe destacar que essa população dirigiu-se ao Rio de Janeiro e Salvador, inicialmente. Ali, o trabalho escravo foi utilizado ao longo do todo o período Colonial e Imperial, especialmente no cultivo da cana-de-açúcar, mas também no de cereais, produtos hortifrutigranjeiros e mandioca; assim como na caça e na pesca, na coleta de madeiras e metais preciosos - mais tarde e em outras localidades; e até em pequenas indústrias, especialmente com o crescimento vegetativo da população, posteriormente (REIS, 2000).

Dessa forma, o que se nota é que a economia se sustentou sobre esta base, a do escravismo. Tanto o é que a Proclamação da República veio logo após a abolição da escravidão em 1888, apenas um ano depois da mesma, já que um dos eixos dessa economia havia se partido.

Cabe lembrar que a experiência indígena de escravidão foi frustrada, tendo em vista, principalmente, o próprio sistema imunológico dos índios que não resistia às doenças trazidas pelo europeu (SCHWARTZ, 2011; FAUSTO, 2015); além de sua falta de experiência para o trabalho regido por regras e horários, um modelo que eles desconheciam, porém mesmo assim, e em menor proporção a escravidão indígena também se manteve.

Os negros, ao contrário possuíam experiência com o trabalho rígido e resistência física, além de o seu deslocamento gerar muito mais lucros aos escravistas, por isso mesmo, eles foram escolhidos. Nesse sentido, importante lembrar que "a propriedade sobre os escravos não se limitava a grandes senhores de engenho fazendeiros e mineradores", de forma que havia aqueles que detinham 2 (dois) ou 3 (três) escravos, somente (REIS, 2000, p. 245).

Contudo, diferentemente do que se pode pensar, os indígenas e os negros também não aceitaram passivamente a escravidão, mas resistiram-lhe, com as armas que tinham, seja por meio das guerras, fugas, do assassínio dos seus senhores e feitores e até do aborto (FAUSTO, 2015). Além das revoltas que visavam a reforma do sistema escravagista e que lutavam por melhores condições de vida e trabalho para os negros. Nesse sentido, pode-se afirmar:

[...] onde houve escravidão houve resistência. E de vários tipos, mesmo sob a ameaça do chicote, o escravo negociava espaços de autonomia com os senhores ou fazia corpo mole no trabalho, quebrava ferramentas, incendiava plantação, agredia senhores e feitores, rebelava-se individual ou 
coletivamente. Houve, no entanto, um tipo de resistência que poderíamos caracterizar como a mais típica da escravidão - e de outras formas de trabalho forçado. Trata-se da fuga e formação de grupos de escravos fugidos. A fuga nem sempre levava à formação desses grupos. Ela podia ser individual ou até grupal, mas os escravos terminavam procurando se diluir no anonimato da massa escrava e de negros livres (REIS; GOMES, 1996, p. 9).

Nesse contexto, ainda conforme Fausto (2015), os índios se saiam melhor, uma vez que conheciam a terra, já o negro, embora não a conhecesse, também fugia e formava pequenas aglomerações, os quilombos, os quais se localizavam, em regra, em locais afastados e de difícil acesso, justamente para dificultar o trabalho de captura dos agentes do Estado Português ou dos particulares, donos desses escravos, embora muitos mantivessem proximidade da cidade e como afirmam Reis e Gomes (1996), tentassem se diluir no anonimato da massa negra livre e escrava, que vivia nessas localidades.

Conforme Reis (2000), as fugas aumentaram consideravelmente no final do séc. XVIII, devido à intensificação do tráfico negreiro, que ampliou de forma significativa a população negra na lida, inclusive de pessoas da mesma etnia; o que, por sua vez, reforçava sua identidade coletiva e a consciência de que era possível lutar contra o número cada vez menor das camadas livres, embora estas detivessem o poder político, do dinheiro e das armas.

Ainda segundo Reis (2000), no contexto das lutas contra a opressão por parte das camadas livres que se beneficiavam da escravidão, havia como pano de fundo simbólico e ideológico o ideário da Revolução Haitiana, de 1790, que serviu de inspiração aos movimentos reformistas; mas a abolição, no Brasil, ainda demoraria cerca de 100 (cem anos) para acontecer.

Por outro lado, essa intensa luta, as revoltas, inclusive por parte de outros setores sociais, contra a escravidão, ocasionavam, por conseguinte, forte reação da classe senhorial, que não queria perder seu privilégio, nem abrir mão de sua "propriedade", o negro. Surge, portanto, a necessidade da criação de núcleos de resistência, que dentre suas formas de luta, escolheu a formação de quilombos, a fim de se livrarem dos grilhões da escravidão, lutarem por melhores condições e reproduzirem seu modo de vida, sua cultura e relações sociais, em um território ameno, que lhes fosse favorável.

Quanto ao conceito de quilombo, outro tema muito relevante ao presente trabalho, é importante destacar que conforme a sua etimologia africana, significa, no 
idioma bantu, da África Central e Centro-Ocidental, "acampamento", sendo que também se refere aos rituais de guerreiros e militares em geral, na África CentroOcidental (GOMES, 2003). Conforme o Conselho Ultramarino de 1740, o quilombo era concebido como sendo "toda habitação de negros fugidos, que passem de cinco, em parte despovoada, ainda que não tenham ranchos levantados e nem se achem pilões nele" (ALMEIDA, 2002, p. 47).

No Brasil, os quilombos, formados especialmente a partir dos séculos XVII, XVIII e XIX, foram locais em que os negros puderam reproduzir seu modo de vida, criando ali uma identidade própria, com toda a riqueza social e cultural; formando também seus focos de resistência à escravidão, os quais, por sua vez, preocupavam os senhores e a própria Coroa Portuguesa, razão pela qual eram combatidos com tanta violência. A formação dos quilombos se dava em razão das condições de trabalho e das limitações da vida na senzala, além da crueldade praticada pelos senhores contra seus escravos; de forma que os negros precisavam de espaços independentes em que pudessem se recompor.

Dentre os quilombos, a grande referência, não apenas em termos numéricos, mas também de organização, foi o quilombo de Palmares, que servia como esperança e foco de inspiração para diversas partes do país, razão que tornou a luta contra ele cada vez mais intensa, até sua completa aniquilação, já que, simbolicamente, sua importância era ainda maior que na prática (MUNANGA, 2006, p. 98). Mas os quilombos, ao contrário do que se imagina, não se formavam apenas por negros, mas por pessoas pobres, que fugiam de alguma condição natural adversa e também por índios, que vinham buscar refúgio ali (ALMEIDA, 2002; GOMES; 2003)

Nesse contexto, criou-se em tais lugares um agrupamento singular, único, que não se caracterizava apenas como áreas de fuga, isolamento e resistência, tal como era pensada a historiografia, até a década de 1970, a qual incluía historiadores como Nina Rodrigues, Artur Ramos, Edison Carneiro e Roger Batiste; mas, algumas vezes, os habitantes dessas comunidades mantinham contato com as cidades, negociando aquilo que lhes fosse essencial, até que a escravidão fosse finalmente abolida (REIS; GOMES,1996).

A abolição da escravidão, entretanto, não trouxe consigo as garantias e o acesso a direitos que por três séculos lhes foram negados. Na realidade, o negro continuou expropriado desses direitos e a própria Lei de Terras, a de $n^{\circ} 601$, de 18 
de setembro de 1850, instituiu, logo em seu art. $1^{\circ}$, que estavam "prohibidas as acquisições de terras devolutas por outro título que não seja o de compra" (BRASIL, 1850, texto digital).

Nesse contexto, a ocupação se mostrava irregular e não era a forma correta de aquisição de terras, o que favoreceu a manutenção do "status quo" do negro no Brasil, marginalizando-o cada vez mais. Deste modo, no período pós-escravidão não se resolveu o problema das desigualdades sociais entre brancos e negros, nem se conferiu a eles as mesmas oportunidades, negando-Ihes a cidadania e os direitos mais essenciais.

Daí a razão da existência de uma dívida histórica com essa população, que hoje justifica as chamadas políticas de ação afirmativa, tais como as cotas raciais em universidades e em concursos públicos; especialmente conseguidos por meio da luta, afinal, não há direito que não seja conseguido dessa forma (ILERING, 2008).

Essa luta se constituiu por meio de movimentos sociais, tais como 0 Movimento Negro Brasileiro (MNU) e a Frente Negra Brasileira, que ainda hoje lutam contra o racismo, buscam representação política e o resgate dessa dívida histórica supra mencionada. Nesse contexto de lutas e conquistas, uma das mais importantes foi a inclusão, no texto da Carta Magna de 1988, do art. 68 do Ato das Disposições Constitucionais Transitórias (ADCT), onde se lê que "aos remanescentes das comunidades dos quilombos que estejam ocupando suas terras é reconhecida a propriedade definitiva, devendo o Estado emitir-lhes os títulos respectivos" (BRASIL, 1988, texto digital) ${ }^{5}$.

Assim, foi com base nesse artigo que comunidades quilombolas puderam assegurar a regularização fundiária desses espaços, historicamente ocupados por tais comunidades, espaço esse que lhes serve como recurso de subsistência e também de lugar em que pode reproduzir seu modo singular de vida, sem interferências externas. Para além disto, segundo O’Dwyer (2002), é o autorreconhecimento como comunidade quilombola, que cabe ao próprio grupo

\footnotetext{
${ }^{5}$ Os direitos previstos no art. 68 estão regulamentados pelo Decreto Federal oㅜ 4.887/2003, de 20 de novembro de 2003. Este decreto institui em seu artigo $1^{\circ}$ sobre as etapas legais a serem seguidas na condução do processo de regulamentação das terras dos remanescentes de quilombos. Art. 1ㅇ Os procedimentos administrativos para a identificação, o reconhecimento, a delimitação, a demarcação e a titulação da propriedade definitiva das terras ocupadas por remanescentes das comunidades dos quilombos, de que trata 0 art. 68 do Ato das Disposições Constitucionais Transitórias, serão procedidos de acordo com o estabelecido neste Decreto (BRASIL, Decreto ํㅡ 4.887, de 20/11/2003, texto digital).
} 
étnico, com critérios próprios de pertencimento e exclusão que lhes assegura esse direito ao território de seus antepassados; processo que comunidades remanescentes de quilombolas como a da Ilha de São Vicente tiveram que passar, com reuniões e formulação de documento reconhecendo-o.

Isso é fundamental para a formação da consciência crítica de pertencimento, para a luta pelos direitos assegurados na Constituição e para a própria construção da identidade coletiva e individual. Assim sendo, dados atualizados da Fundação Cultural Palmares (FCP), até dezembro de 2018, dão conta de que no Brasil há pelo menos 3.212 comunidades quilombolas, das quais 533 estão em processo de análise e 2.685 receberam suas certidões de reconhecimento (BRASIL, 2018).

Essa certificação é essencial para que se possa requerer a titulação do território e sua posse definitiva, por meio do Instituto Nacional de Colonização e Reforma Agrária (INCRA). Isto, especialmente frente ao interesse de grandes latifundiários, que visam a tomada dessas terras, muitas vezes.

A história do movimento quilombola no Brasil, portanto, é uma história de lutas, desafios e impasses e quanto às comunidades do Estado do Tocantins e, inclusive da llha de São Vicente, a luta também se fez essencial, a fim de se garantir não apenas o território, mas seu meio de subsistência e de reprodução de seu modo de vida; razão pela qual, também, muitas dessas comunidades buscaram o seu reconhecimento frente ao Poder Estatal.

De acordo com Salles (1983) e Palacín (1994), historicamente, o negro foi trazido ao estado de Goiás, atual Tocantins, com a descoberta do ouro e o escravo resistia em média apenas 7 (sete) anos, dado as condições de vida, de trabalho e a crueldade com que eram tratados. Do mesmo modo que em outros locais, também ali, o aumento da população negra, especialmente da mesma etnia, fez surgir um número cada vez maior de rebeliões e fugas; e com as condições naturais do relevo acidentado, a hidrografia $\mathrm{e}$ as matas densas o favoreciam, formaram-se os quilombos.

Importante destacar, ainda, conforme a Fundação Cultural Palmares (FCP $)^{6}$, acerca do reconhecimento das comunidades Tocantinenses como remanescentes

\footnotetext{
${ }^{6}$ A Fundação Cultural Palmares (FCP) é uma entidade vinculada ao Ministério da Cultura (MinC) foi criada mediante autorização da Lei oํ 7.668/88 e materializada pelo Decreto oㅜ 148/92, com objetivo de promover e preservar a cultura e a arte afro-brasileira e suas diversas expressões (Discponível em: http://www.palmares.gov.br/?page_id=95).
} 
dos quilombos, que foram reconhecidas como tal a da llha de São Vicente, em 2010, no município de Araguatins; e Carrapiché, Ciriaco e Prachata, no município de Esperantina, em 2015; todas localizadas no extremo Norte do Estado do Tocantins, região do Bico do Papagaio, na Bacia do Tocantins-Araguaia. Mesmo assim, podese afirmar que pouco se sabe sobre essas comunidades, razão que suscitou a presente pesquisa, até porque o próprio autorreconhecimento das mesmas, especialmente da comunidade da llha de São Vicente, é recente.

Atualmente, no estado do Tocantins, registram-se pelo menos 45 comunidades quilombolas certificadas pela Fundação Cultural Palmares (FCP), o que é essencial para essas comunidades, não apenas para lhes garantir o direito ao território em que seu modo de vida se constitui, mas, principalmente, para assegurar a efetivação do rol das políticas afirmativas, que lhes permitem ingressar em universidades públicas e serviço público, resgatando, a dívida histórica do país com essa população.

\section{Território, cultura e identidade quilombola na Ilha de São Vicente}

O município de Araguatins foi fundado por volta de 1868, com a chegada do maranhense Vicente Bernardino Gomes e está localizado na Microrregião do Bico do Papagaio, no norte do Estado do Tocantins, às margens do rio Araguaia, fazendo parte da chamada "Amazônia Legal" e abrangendo uma área total de 26.625,286 $\mathrm{km}^{2}$. Foi elevado à condição de município no ano de 1931, derivando o próprio nome da cidade dos rios Araguaia e Tocantins, que cortam a região (DUARTE, 1970; BRASIL, 2010)

Nesse sentido, o mapa (figura 1), ilustra bem a localização do município de Araguatins, com destaque para a Comunidade Remanescente de Quilombo llha de São Vicente. Salienta-se que o acesso à comunidade quilombola llha de São Vicente é realizado por meio de transporte fluvial, caracterizado por pequenas embarcações e voadeiras, que são barcos de porte médio. 
Figura 1 - Mapa do Estado do Tocantins, o Município de Araguatins e a comunidade remanescente de quilombo Ilha de São Vicente em destaque

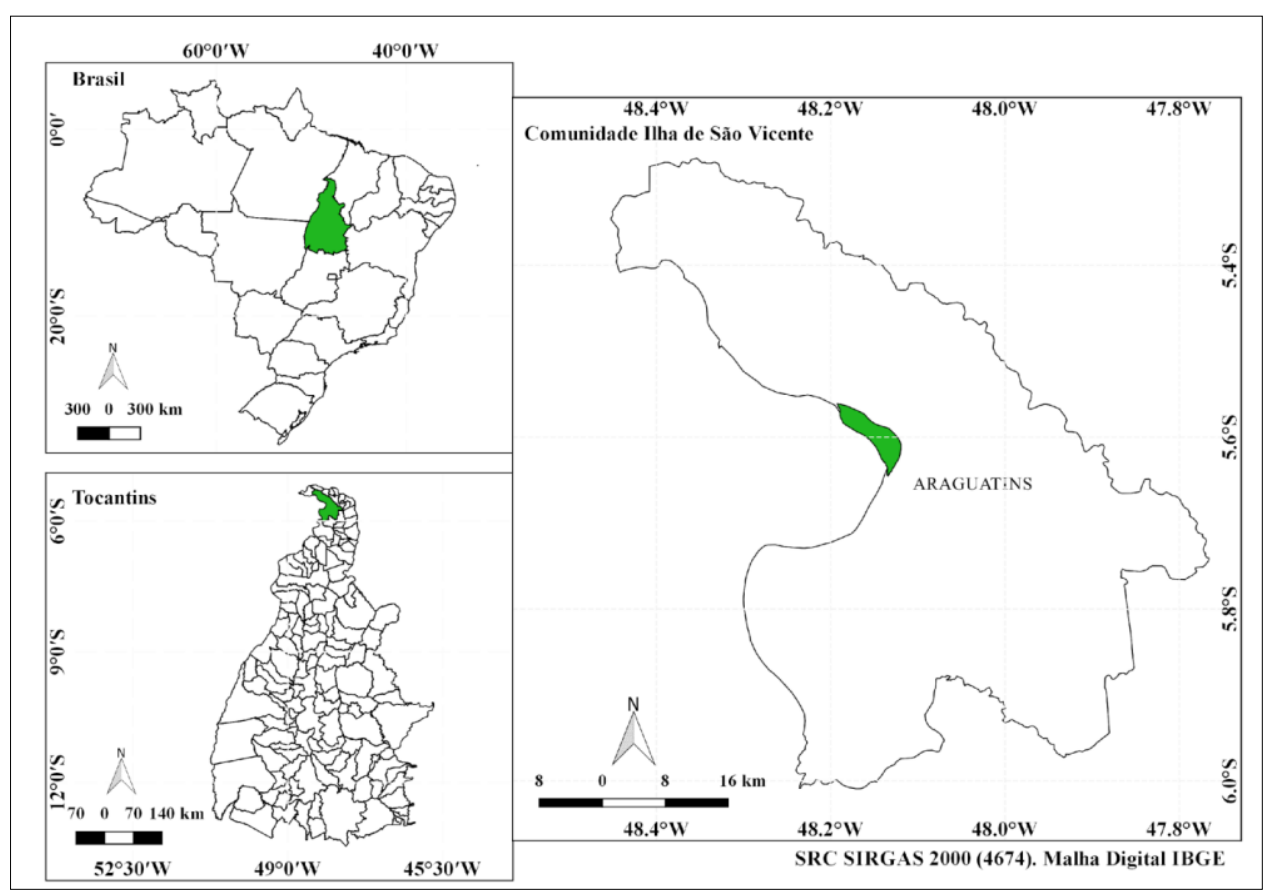

Fonte: Guerino (2018).

Segundo Lopes (2014), os diálogos que se estabeleceram na própria comunidade e os documentos encontrados sobre a ocupação do território, os primeiros habitantes da localidade eram escravizados, dois casais vindos de Carolina do Maranhão, em 1869. Na época, os quatro escravos referidos, pertenciam a Vicente Bernardino e permaneceram nessa condição até a abolição; o que significa que não se formou a partir da fuga, mas da libertação dos escravos, em 1888.

Os dois casais, uma vez libertos, fixaram residência, um na llha de São Vicente, na terra que pertencia a Araguatins. O outro casal, por sua vez, estabeleceu-se nas margens do Araguaia, já na divisa do Pará com o Tocantins (LOPES, 2014). Vale salientar, que mesmo tendo se fixado em locais distintos, as duas famílias mantinham uma rede de sociabilidade, tais como, nas atividades laborais e festividades, a exemplo de casamentos, inclusive unindo-se as famílias por meio do matrimônio de seus filhos e netos.

Fontes orais dos interlocutores da pesquisa com os remanescentes quilombolas da Ilha São Vicente dão conta dessa união entre as famílias, muito embora se perceba certas discordâncias sobre alguns fatos, situação compreensível, tendo em vista a forma como cada um vivencia de forma particular 
as lembranças. Sobre isto, Halbwachs (2006, p. 29), salienta que se pode "[...] reconstruir um conjunto de lembranças de maneira a reconhecê-las porque eles concordam no essencial, apesar de certas divergências", sem que essas divergências prejudiquem de forma essencial as histórias passadas tradicionalmente, acerca das origens dessa comunidade.

Tal é o caso, por exemplo, do interlocutor E1 (2017) e sua irmã entrevistada E2 (2017), que com seu jeito simples e acolhedor, falam de maneira bem enfática sobre o seu avô, o Sr. Henrique Julião Barros, que teria sido o primeiro morador da Ilha de São Vicente.

Por outro lado, sabe-se que o que se tem de memória, mesmo daquilo que se ouviu falar, já que aqueles que viveram a realidade da escravidão já não se encontram mais vivos, são, na verdade, retalhos de estórias, uma vez que os mais velhos não gostavam de falar sobre esse período de dor e sofrimento. Segundo E2 (2017), acerca de certas histórias de sua ancestralidade, relata:

\begin{abstract}
Num me lembro. Purque o papai num gostava nem de falá desses assunto. Acho que purcausa do sufrimento do pai dele no tempo de iscravo. A irmã do meu pai, qui era a mais velha é qui contava algua coisia pra nois, aqui aculá. Disse qui tia o ispiaço quebrado esse qui foi iscravo... disse qui tia aquela torona de pau disse qui botava nas costa e ficava suquiando... disse que ele era um homi qui tia muita força, disse que nessa região puraqui era o homi qui tia mais força. Aí disse qui nisso ele quebrô o ispiaço, era cacundim. Eu num cuinci ele não. Mermo quando eu escutava a tia Brasilina contar as história eu ficava cum pena de meu avô. Disse que viero cum esse povo de Carulina pra cá... num sei se foi na saída de lá vendero eles, os escravo, ô se foi na chegada daqui de Araguatins (E2, 20/10/2017, p. 2, grifos nossos).
\end{abstract}

Esse silêncio, contudo, não significa esquecimento, já que a memória também pode ser vista, nesse caso, como uma construção coletiva, de modo que uma pessoa não sabe dizer, porque seu antepassado silenciou sobre isso, ou um assunto sobre o qual se sabe apenas uma parte, outra pessoa complementa, os documentos revelam, ou outras pesquisas já realizadas dão conta. De qualquer forma, o Relatório Antropológico da Comunidade Remanescente de Quilombo llha de São Vicente, elaborado por Rita Domingues Lopes (2014), também menciona que os primeiros habitantes da ilha foram o casal de escravos Julião Barros e D. Serafina Benedita Batista, sendo que um de seus filhos foi Henrique Julião Barros, o que dialoga com o relato do interlocutor E2 (2017), supracitado. 
Do mesmo modo, outras pessoas mais velhas, de fora da ilha, mas que também viviam na região à época, ajudam a reconstruir os fatos. Tal é o caso de depoimentos como o de Pedro Duarte, obtido por Lopes (2014), conforme segue:

[...] Aí quando foi abolida a escravatura ele mandou eles irem para a ilha.
Lá num tinha ninguém nessa ilha. Num tinha ninguém. Aí mandou eles
ir para lá: 'vá pra lá que aí dá pra você viver'. Ele tinha uma mulher, e
ele foi o primeiro morador dessa ilha foi ele [...] Os primeiros foram
eles, quando o Henrique que era o escravo foi pra lá num tinha
ninguém nessa ilha, é verdade pura e certo, foi o primeiro morador
dessa ilha foi ele, o Henrique. O primeiro morador dessa ilha foi o
Henrique, palavra de certo (LOPES, 2014, p.54, grifos nossos).

Portanto, as terras teriam mesmo sido recebidas por doação e o que se percebe em todas as falas dos membros da comunidade é a sensação de pertencimento. Isto também vale por parte daqueles que deixaram a ilha em busca de melhores condições de vida, dirigindo-se para a comunidade de São Raimundo ou mesmo Araguatins, mas as redes de sociabilidade e os traços culturais para com os parentes e demais membros da comunidade que ficaram na ilha foram mantidos.

Nesse sentido, conforme Cardoso de Oliveira (2006, p.61), "a ideia de comunidade não se esgota no território étnico, mas se estende a membros dessas mesmas comunidades que emigram para as cidades". Deste modo, a saída da ilha não Ihes retira a condição da identidade de quilombolas, nem diminui em nada a importância da comunidade. Mas o fato é que território, assim como a língua, é um indicador de identidade.

Mas essa não é a única razão pela qual a luta pela afirmação das comunidades remanescentes de quilombos passa por essa necessidade de reconhecimento da titulação da terra. Na realidade, a própria ideia de comunidade, de identidade enquanto grupo étnico, perpassa a noção de território e, uma vez que thes foi retirado isso dos seus antepassados, os quais foram arrancados de sua terra, é hora de se resgatar essa dívida, conferindo a esses povos o direito ao espaço em que esses mesmos antepassados se estabeleceram e fundaram seu modo de vida singular.

Assim, não apenas o território pertence a essas comunidades, mas estas também lhes pertencem, na medida em que é nessa terra que eles encontram 0 sentido de suas existências e suas raízes, onde reproduzem seu modo de vida e subsistem, apesar das dificuldades. 
Contudo, levando-se em conta a comunidade em estudo, e frente às abordagens territoriais de Haesbaert (2007), percebe-se que, de fato, existe mais de um tipo de configuração de território na Ilha de São Vicente. Dessa forma, têm-se os espaços que são de lazer e os que pertencem aos fazendeiros, os quais se enquadram na lógica capitalista de dominação econômica; e o espaço dos quilombolas, que segue outra lógica, a da apropriação cultural e simbólica, já que o grupo atribui significados às relações do cotidiano, tornando o território um espaço de comunhão de significados e valores, imprimindo-lhe, em seu uso físico e simbólico, as marcas de sua identidade.

Nesse sentido, Laraia (2009) adverte sobre a semelhança da natureza dos homens, de tal modo que o que os diferencia é sua cultura, os seus valores e significados que ele imprime nas relações que estabelece cotidianamente. Nesse diapasão, Furtado, Sucupira e Alves (2014, p. 107), dispõem que a cultura, "é definida como a totalidade de reações subjetivas e sociais que caracterizam a conduta dos indivíduos componentes de um grupo", de tal forma, podemos dizer que comportamentos sociais dos quilombolas da llha de São Vicente devem ser compreendidos a partir dos traços culturais da comunidade.

Dessa maneira, a cultura se constitui através da reprodução dos modos de vida, em que existe essa comunhão de experiências e saberes, com significados peculiares e atributos simbólicos estabelecidos pela coletividade. Isso não é diferente na comunidade que se formou na llha de São Vicente. Ali se estabeleceu uma identidade, que não é apenas pessoal, mas coletiva e que se estabeleceu sim a partir do território, dos valores e do sentimento coletivo de pertencimento. Daí a importância simbólica desse espaço. Neste sentido, é que Castells (1999), salienta ser a identidade uma fonte de significados e experiências de uma "nação", categoria que no caso em estudo tomamos como os remanescentes quilombolas da Ilha de São Vicente, os quais comungam valores e significados para o mundo que os rodeia.

Ademais, importante destacar que a identidade étnica se diferencia de outras formas de identidade, na medida em que se orienta para o passado, fundada que está na memória coletiva, conforme Poutignat e Streiff-Fenart (1988). Situação que se percebe claramente na comunidade da llha de São Vicente, algo que reforça ainda mais a noção de que ali se tem mesmo uma comunidade remanescente dos antigos quilombos, mesmo que não se haja composto de negros que fugiram da 
escravidão, mas que se livraram dela com a Lei Áurea de 1888 e buscaram um território para constituir seu modo de vida e de ser.

\title{
Lutas e conflitos no processo de reconhecimento do território remanescente quilombola na llha de São Vicente
}

O processo de reconhecimento do território quilombola na Ilha de São Vicente passou por grandes sobressaltos e os moradores sofreram reveses na busca por um direito que lhes assiste. Isto é, manter-se na terra cultivada por seus antepassados, no local em que se reproduziu um modo de vida peculiar, onde se formou a comunidade, com identidade própria e noções de pertencimento.

Ocorre que, da mesma forma que pessoas da comunidade dirigiram-se a outros locais, buscando melhoras em suas condições, também outras, de fora dela, acabaram despertando seu interesse por aquelas terras, fosse para 0 desenvolvimento da agricultura ou para criação dos animais.

Essa ocupação não gerou conflitos, inicialmente, uma vez que a comunidade não se sentiu ameaçada, nem teve uma visão capitalista de propriedade. Sobre isto, um dos interlocutores, cuja idade é de 76 anos, relata:

\footnotetext{
Nessa épuca agente quase assim num tia importância assim pur terra, só mermo pela aria qui agente tava ocupando, trabaiando... aí ele vei pa... aí arrumô um pedacinho lá, ua morada... aí tia muito espaço, aí ele tiro um pedaço grande. Aí ficô trabaiando, prantô capim... tia já um pôco de gado e colocô um pôco de gado aí (E3 13/10/2017, p. 3).
}

Como se observa, o valor econômico da terra era desconsiderado, especialmente quando se sabe tratar de uma comunidade em que o trabalho era coletivo e o resultado era compartilhado.

Contudo, essa ocupação por pessoas de fora da comunidade começou a se dar mais massivamente e aqueles que o faziam passaram a comercializar as terras cedidas pela comunidade. Surge então a figura do latifundiário, por volta da década de 1970 e com ele os primeiros conflitos. Nessa perspectiva, importante trazer fragmentos de um documento que comprova a ocupação quilombola na região, que se trata da certidão de óbito de Maria Francisca Barros.

\author{
REPÚBLICA FEDERATIVA DO BRASIL \\ RESTRO CIVIL DAS PESSAS NATURAIS \\ Certidão de Óbito \\ NOME \\ MARIA FRANCISCA BARROS \\ MATRÍCULA - não consta
}




\begin{tabular}{|c|c|c|c|c|}
\hline $\begin{array}{l}\text { SEXO } \\
\text { Feminino }\end{array}$ & $\begin{array}{l}\text { COR } \\
\text { Parda }\end{array}$ & $\begin{array}{c}\text { PROFISSÃO } \\
\text { Prendas Domésticas }\end{array}$ & $\begin{array}{r}\text { ESTADO Cl } \\
\text { Casada com } 53\end{array}$ & $\begin{array}{l}\text { VIL E IDADE } \\
\text { anos de idade }\end{array}$ \\
\hline DATA DE I & ISCIME & NTO (POR EXTENSO) & DIA & MÊS ANO \\
\hline Não consta & o termo & & $x x$ & $x x \quad x x$ \\
\hline $\begin{array}{l}\text { DOMICÍLIC } \\
\text { Ilha São Vi }\end{array}$ & $\begin{array}{l}\text { RESID } \\
\text { nte, Mu }\end{array}$ & $\begin{array}{l}\text { ENNCIA } \\
\text { nicípio de Araguatins - }\end{array}$ & & \\
\hline $\begin{array}{l}\text { NATURAL } \\
\text { Goiana }\end{array}$ & ADE & $\begin{array}{l}\text { DOCUMENTO DE IDEI } \\
\times x x x x x x x x x x x x x x x x\end{array}$ & $\begin{array}{l}\text { ITIFICAÇÃO } \\
x x x x x\end{array}$ & $\begin{array}{c}\text { ELEITOR } \\
x x x x\end{array}$ \\
\hline
\end{tabular}

DATA E HORA DO FALECIMENTO DIA MÊS ANO Vinte e Sete de Novembro de Mil Novecentes e Ciquenta e Nove 17/11/1959 Às Quatro horas e Zero minutos

Local e Data: Araguatins. 10/04/2014

Oficial Julia Labres Rodrigues

(CERTIDÃO óbito de 10/04/2014, Acervo documental da Comunidade Ilha de São Vicente, grifos do autor).

Conforme se observa na certidão de óbito, consta como domicílio de Maria Francisca Barros, a Ilha de São Vicente, cujo falecimento deu-se em 17/11/1959 e cuja idade era de 53 anos, portanto seu nascimento embora não conste no documento remonta a primeira década do século XX. Apesar disso, os posseiros passaram a questionar a legitimidade da moradia dos remanescentes de quilombos naquelas terras, alegando propriedade sobre elas, utilizando-se, inclusive, de meios jurídicos para retirá-los dali.

A princípio o empreendimento teve sucesso, por meio de uma ação de reintegração de posse movida por Edelves dos Passos de Carvalho, viúva de José Pereira Fernandes, em desfavor de Salvador Batista Barros, em 28 de novembro de 2001 (TOCANTINS. Poder Judiciário - Processo no 2504/01 - Comarca de Araguatins. Cartório da Família, fls 02, 28/11/2001). De forma que após longo processo de tramitação, em 26 de outubro de 2010 surge a ordem de despejo que retira as famílias quilombolas, em um ato de violência física e simbólica, que causou reações, tanto na comunidade do entorno como na mídia regional.

Assim, com o apoio da mídia, de pessoas ligadas aos movimentos sociais e, inclusive, de uma pesquisadora que atuava junto à comunidade, a Sra. Leonídia Coelho, que os auxiliou no autorreconhecimento enquanto grupo étnico remanescente de quilombo, e, portanto, sujeitos de direitos, inclusive quanto ao espaço ao qual pertenciam enquanto comunidade, conseguiu-se retornar parte do território. 
Ainda, segundo um dos interlocutores da comunidade, outra pessoa que teve grande relevância no cenário de luta pelo reconhecimento do território foi Benvinda Monteiro, a qual conhecia muito bem a história da comunidade e dispôs-se a fazer uma Declaração Pública, conforme segue:

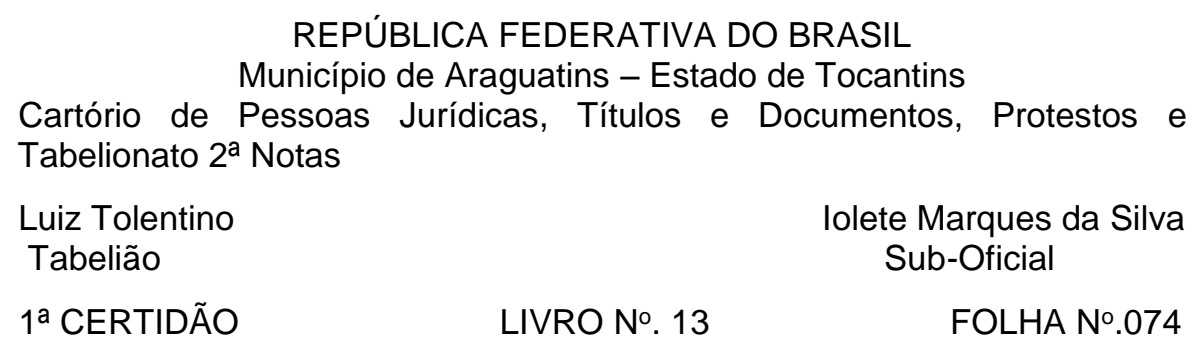

Certifico a pedido verbal de parte interessada que revendo os livros deste Serviço Notarial, dentre eles o Livro n⿳013, às Folha 074, verifiquei constar a Escritura Pública do seguinte teor.

ESCRITURA PÚBLICA DECLALATÓRIA que nestas notas faz BENVINDA MONTEIRO CORREA, na forma abaixo

SAIBAM quantos esta pública escritura declaratória virem, que aos vinte e cinco (25) dias do mês de Outubro do ano de dez mil e dez (2010), nesta cidade de Araguatins, estado de Tocantins, em cartório, perante min SubOficial, compareceu como outorgante declarante BENVINDA MONTEIRO CORREA, brasileira, viúva, aposentada, portadora da CI-RG no 332.934SSP/GO e inscrita no CPF/MF n० 575.740.141-91, residente e domiciliada à Praça da Bandeira $n^{\circ} 108$, centro, nesta cidade de Araguatins, a outorgante declarante declara para os devidos fins para quem possa interessar que conhece o Sr. SALVADOR BATISTA BARRO, como também os seus familiares; que é sabedora que a família do Sr. Salvador é descendente de escravos que para cá vieram ainda no século XIX; que o avô do Sr. Salvador chamava-se Henrique Barros conhecido pela alcunha de Henrique Cacete e que era escravo do Sr. Bernardo Martins o qual recebera pelo pagamento de uma dívida na cidade de Carolina-MA. Após a abolição da escravatura Henrique Cacete foi residir na llha São Vicente, neste município de Araguatins-TO, tendo sido o seu primeiro morador, Henrique Cacete teve 06 (seis) filhos, sendo: José Henrique, Pedro Henrique, Brasilina Henrique, Raimunda Henrique e Domingas Henrique; todos os filhos do Sr. Henrique Cacete, nasceram na Ilha São Vicente. O Sr. Henrique criava gado na ilha São Vicente par o Sr. José Miguel (Síriio) um dos primeiros moradores de Araguatins; quando o Sr. José Miguel mudou-se para Tocantinópolis, deixou para José Henrique todo o gado que tinha na ilha. E que Sr. Jose Henrique teve 07 (sete) Filhos sendo: Eugênio Batista Barros, Maria Bastista Barrros, Juarez Bastista Barros, Domingas Batista Barros, Vicência Batista Barros, Pedro Batista Barros e SALVADOR BATISTA BARROS; que todas essas pessoas citadas nasceram e se criaram na llha São Vicente. Desse ainda a outorgante que repetirá em juízo se necessário for tudo que declarou, sob as penas da lei. Trasladada por Certidão, era o que se continha em referido ato, está tudo conforme ao próprio original. Eu, lolete Marques da Silva, Sub-Oficial, que a fiz extrair, conferi, subscrevo, dou fé e assino a presente. EMOLUMENTOS: $R \$$ 19,65, Funcivil: R\$ 9,45, TFJ: R\$ 5,90 ISS: 0,98, Centrais R\$12,00, Tx. Processamento: Não incide, TOTAL: R\$47,98.

O referido é verdade e dou fé. 
Araguatins-TO, 31 de janeiro de 2018.

Iolete Marques da Silva

Sub-Oficial

(CERTIDÃO №. 13, folha №, 074, de 31/01/2018. Cartório de Pessoas Jurídicas, Títulos e Documentos, Protestos e Tabelionato $2^{2}$ Notas. Araguatins-TO, grifos do autor).

Nesse sentido, Benvinda Monteiro, fez essa Declaração Pública registrada em cartório onde conta a história da família Barros e ainda informa que o livro de Leônidas Duarte "De São Vicente à Araguatins: Cem anos de história" (1970), também traz relatos dessa dívida resgatada com os ex-escravos, de modo que aquele território Ihe teria sido doado ao final do período de escravidão.

Mesmo com o retorno à llha de São Vicente, ainda demorou algum tempo até que se conseguisse o reconhecimento como categoria social com "trajetória histórica própria, dotado de relações territoriais específicas, com presunção de ancestralidade negra relacionada à resistência à opressão histórica sofrida" conforme estabelecido no Decreto 4.887/2003 (BRASIL, Decreto 2003, texto digital). Entretanto, o reconhecimento favoreceu e fortaleceu a ideia de identidade como grupo étnico, no que diz respeito à permanência nesse espaço que foram dos seus antepassados, trazendo para a própria comunidade uma nova perspectiva no que se refere a enxergar sua ancestralidade e sua história.

\section{Desafios e conquistas da Comunidade Quilombola llha de São Vicente}

Importante destacar que, historicamente, as comunidades quilombolas se caracterizaram pela ocupação coletiva da terra, tanto na produção de alimentos para a sua subsistência, como na criação de animais, com o mesmo fim. Trata-se, portanto, de uma comunidade que não se enquadra na lógica capitalista de produção, mas, tão somente, volta-se à própria permanência como grupo, produzindo aquilo que lhes é essencial. Nesse sentido tem-se:

[...] a territorialidade desses grupos, a ocupação da terra não é feita em termos e lotes individuais, predominando seu uso comum. A utilização dessas áreas obedece a sazonalização das atividades, sejam agrícolas, extrativistas ou outras, caracterizando diferentes formas de uso e ocupação dos elementos essenciais ao ecossistema, que tomam por base laços de parentesco e vizinhança, assentados em relações de solidariedade e reciprocidade (O'DWYER, 2010, p. 43). 
Atualmente, a Comunidade Remanescente de Quilombo Ilha de São Vicente constitui-se de 48 famílias, as quais ocupam um território de 32 hectares do total de 2.502 hectares (dois mil, quinhentos e dois), na llha de São Vicente. Contudo, apenas 10 famílias ali residem diariamente, devido a questões de educação, emprego e renda.

Ocorre também que a região se encontra muito devastada, especialmente devido à ocupação agropecuária e aos incêndios ocorridos no período de estiagem. Um dos elementos bem característicos da região é o coco babaçu, que é utilizado pela comunidade integralmente, desde a sua palmeira, como adubo, até a casca, da qual se faz carvão, o qual serve para o cozimento os alimentos e a palha, para cobrir as residências (DIÁRIO de Campo, 28/11/2016). Uma interlocutora de 89, relata a importância desse produto.

O Babaçu, nois quebrava muito coco babaçu, nois treis as treis irmã. Nois comprava ropa era quebrando coco e vendendo... quando o papai pudia ele dava, mais nois mais é qui comprava. Nois custurava tambeim, quando era no tempo dos festejo in Araguatins nois passava o dia quebrando coco e quando era di noite ia pa custura. Nois custurava a noite todia cum lamparina de querosena aquilo dá ua fumaça (E2, 20/10/2017, p. 5).

A seguir (Figura 2), são imagens que revelam essa relação com a terra e com os recursos naturais que a mesma oferece.

Figura 2 - Utilização dos recursos naturais pela comunidade.

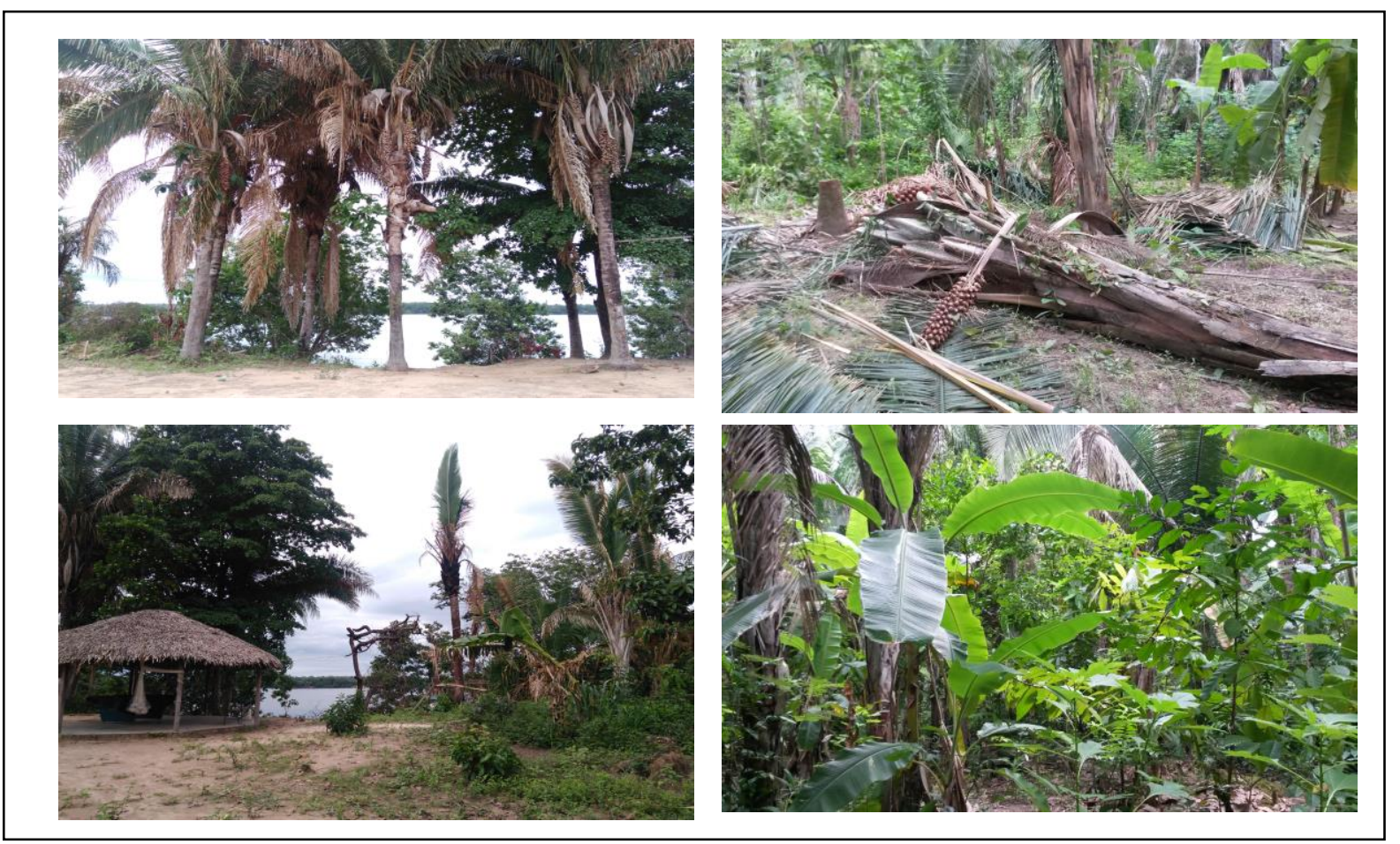


Fonte: Do autor (2017).

A agricultura, na comunidade volta-se à subsistência, ocupando tão somente $2 \%$ (dois por cento) do território total da ilha. Dentre os produtos cultivados apontase feijão, mandioca, milho, abóbora, batata doce, banana, abacaxi, hortaliças, além da criação de animais (DIÁRIO de Campo, 12/10/2017). Contudo, não há excedente para a comercialização.

A grande vantagem de tudo isso, são os benefícios ao próprio meio ambiente, uma vez que não se utiliza agrotóxicos, o que torna a uso do solo uma atividade sustentável, permitindo-se às futuras gerações que também se utilizem daquelas terras para sua subsistência. Esse tipo de cultivo é uma tradição que se empreende há mais de um século, o que demonstra que a forma de se relacionar com o território é muito semelhante, nas diferentes temporalidades.

Contudo, apesar de a terra ainda ser rica, parte da riqueza da fauna já não existe mais, tal como o diz um dos entrevistados: "Eles trabaiava de roça! Botava roça, culhia pra subriviver. Pois é... Eles vivia assim... da pescaria. De pescar... pa cumê e vendê. Quebrar coco, tirar o azeite pa cumê e vendê. Caçava pa cumê. Nesse tempo era rico a terra" (E1, 01/10/2017, p. 5).

Assim, houve tempo na ilha em que havia maior abundância de peixes e caça em geral, em que se plantava a mandioca para a comercialização, afirmam os moradores, mas, devido à ocupação dos fazendeiros, muito disso já desapareceu. Dada a importância de que esses territórios sejam extensos, para preservar não apenas a natureza, mas o modo de vida daqueles que se fixaram ali tradicionalmente (DIÁRIO de Campo, 12/10/2017).

Mas nem só de desafios vive essa comunidade, também houve vitórias ao longo dos últimos anos, tais como a percepção de uma identidade cultural e social e da territorialidade como elemento-chave nessa construção; a quantidade de estudantes que adentraram ao Ensino Superior, graças, principalmente, às políticas de ação afirmativa e que, atualmente, oferecem suporte técnico à comunidade. Ou seja, as políticas de desenvolvimento que o Ministério do Desenvolvimento Agrário vem desenvolvendo na comunidade, conferindo-Ihes também essa assistência técnica, com recursos do Governo Federal (BRASIL, Incra, 2018).

De acordo com os interlocutores da Comunidade Quilombola Ilha de São Vicente, tem sido importante a ação desses acadêmicos quilombolas dos cursos de 
Ciências Biológicas, Agronomia e Computação, na construção de projetos que tendem a melhorar a vida na comunidade e reforçam o vínculo com a terra.

Também se tem favorecido ali a produção sustentável, com agências de fomento envolvidas, tais como a Fundação Banco do Brasil, o BNDES e o próprio Governo Federal; no desenvolvimento de programas como o ECOFORTE (Programa de Fortalecimento e Ampliação das Redes de Agroecologia, Extrativismo e Produção Orgânica), tal como se observa nas imagens a seguir (Figura 3 e 4).

Figura 3 - Horta assistida Ecoforte.

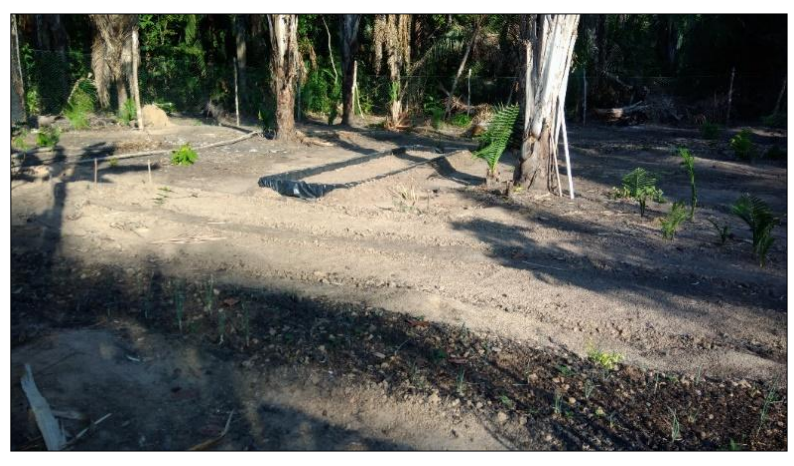

Fonte: Do autor (2017).
Figura 4 - Horta assistida Ecoforte.

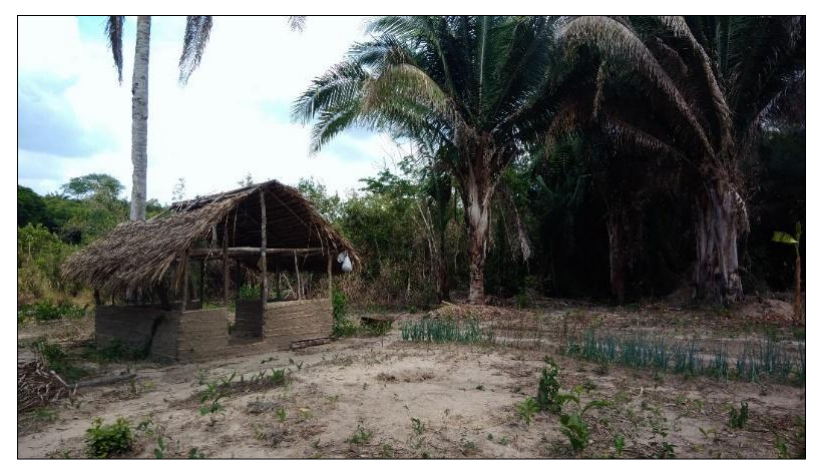

Fonte: Do autor (2017).

Outro ponto diz respeito à manutenção das tradições da comunidade, seja na religiosidade, com a participação dos habitantes em procissões, aulas de catequese, com resquícios de sua religiosidade tradicional ou do sincretismo religioso; seja na construção de casas e utensílios que seguem os moldes tradicionais repassados dos antepassados, tal como se observa na seqüência (Figura 5).

Figura 5 - Habitações e utensílios nos moldes tradicionais.

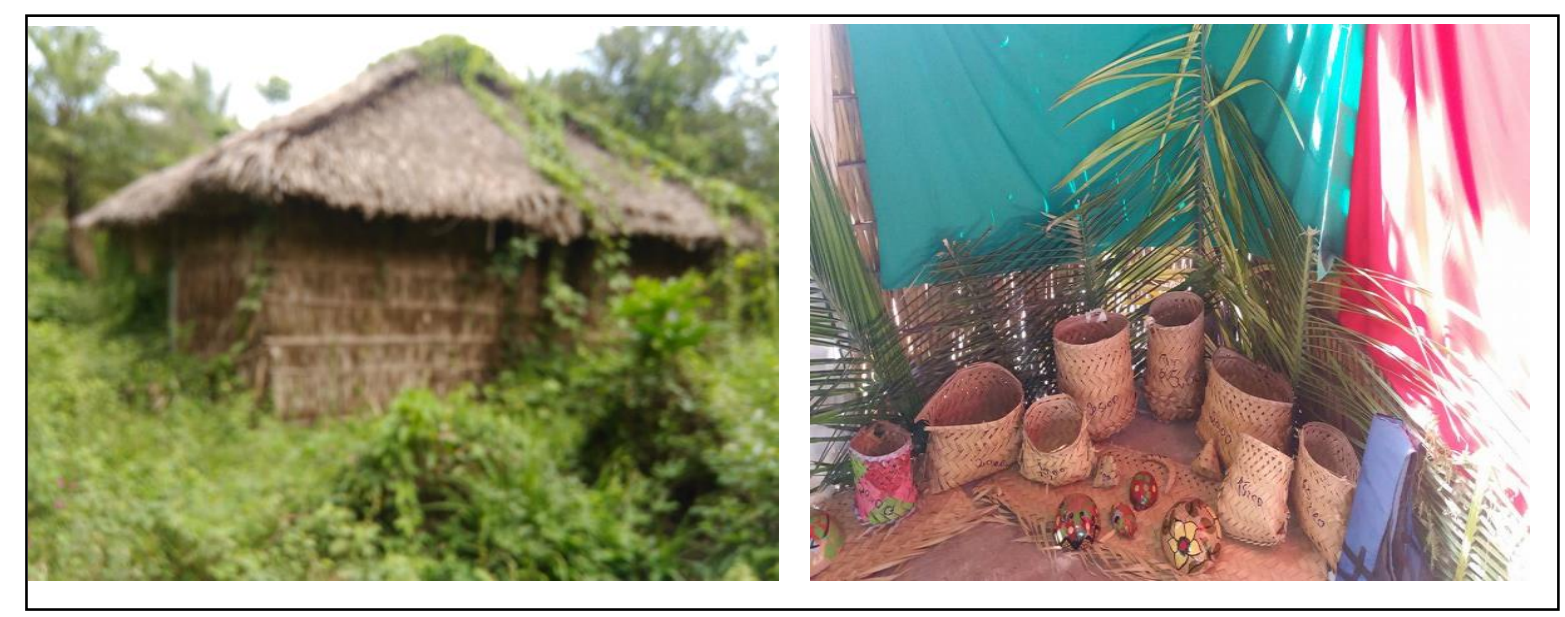

Fonte: Do autor (2017). 
Como se vê a religiosidade se encontra muito presente na comunidade, com a participação dos fiéis nos rituais religiosos, sem, contudo, se perder as raízes da tradição. Portanto, o tradicional se une à modernidade das novas técnicas empreendidas pelos acadêmicos e agências de fomento, para lembrar que é possível inovar sem perder a essência do que caracteriza uma comunidade, sem perder sua identidade.

Assim a territorialidade quilombola da Ilha de São Vicente é manifestada por meio do cotidiano de seus moradores ao utilizar os recursos naturais para suprir suas necessidades, como as diversas formas de aproveitamento do coco babaçu, o uso da água do rio para a higiene pessoal, para realizar as tarefas domésticas e para o lazer.

\section{Considerações Finais}

O que se percebe, após o estudo empreendido na comunidade quilombola da Ilha de São Vicente, é que sua territorialidade é fundamental na formação da identidade dessa comunidade, ela faz parte de sua vida cotidiana, uma vez que os moradores se utilizam dos recursos naturais para suprir as próprias necessidades, especialmente no que diz respeito a alimentos.

O que também se percebe é que a comunidade vem evoluindo muito, graças não apenas ao texto da Constituição Federal de 1988, do art. 68 no Ato das Disposições Constitucionais Transitórias (ADCT), que os tornou sujeitos de direitos em relação ao território que ocupam. Mas, principalmente, porque existem pesquisadores e entidades, movimentos de luta em favor do povo negro, que se conscientizaram desses direitos e levaram esse conhecimento até essas localidades.

Nesse sentido, a sensação de pertencimento, por meio do autorreconhecimento torna-se a certeza de se pertencer realmente a esse grupo, único, singular, rico em cultura e em suas manifestações sociais, sejam aqueles que já nasceram na comunidade ou aqueles que por meio do casamento, principalmente, adotaram-na como seu espaço de vida. O mais importante é que, embora o conhecimento venha do meio acadêmico, das instituições de luta social, ou das organizações públicas, parte da própria comunidade esse reconhecimento de ser quilombola, e de que é preciso lutar pelos direitos que lhe foram negados aos seus 
antepassados e pelo resgate dessa dívida histórica que o Brasil tem com o povo negro.

Nesse sentido, é importante também destacar o apoio de entidades governamentais ou ligadas ao Poder Público, no sentido de se oferecer à comunidade possibilidades de se desenvolver, sem perder, contudo, sua identidade, suas formas tradicionais de se relacionarem uns com os outros, com o solo e com o entorno natural. Apesar disso, é importante também que se diga que a criação de fazendas, nessa área que foi doada para eles há tantos anos, por parte de pessoas que seguem uma lógica tão diferente daquela seguida pela comunidade, ameaça seu modo de vida, retira-lhes recursos essenciais a sua subsistência e manutenção do seu modo de vida.

Nesse sentido, não Ihes basta o reconhecimento da identidade quilombola, mas é preciso que, juridicamente, seja dado a eles o direito a essas terras, em definitivo, por meio da titulação em nome da comunidade; já que existe uma dívida histórica com o povo negro que foi a base da construção social, econômica e cultural do Brasil.

\section{Referências}

ALMEIDA, A. W. B. Os quilombos e as novas etnias. In: O’DWYER, E. C. (Org.).

Quilombos: identidade étnica e territorialidade. Rio de Janeiro: Editora FGV. 2002, p. 4381.

BRASIL. Constituição da República Federativa do Brasil de 1988: Ato das Disposições Constitucionais Transitórias. Promulgada em 05 de outubro de 1988. Disponível em ttp://www.planalto.gov.br/ccivil_03/constituicao/constituicaocompilado.htm\#adct>. Acesso em: 05 de junho. 2017.

BRASIL. Decreto № 4.887, de 20 de novembro de 2003. Regulamenta o procedimento para identificação, reconhecimento, delimitação, demarcação das terras ocupadas por remanescentes das comunidades dos quilombos de que trata 0 art. 68 do Ato das Disposições Constitucionais Transitórias. Disponível em <http://www.planalto.gov.br/ccivil_03/decreto/2003/d4887.htm> Acesso em: 05 de junho. 2017

BRASIL. Fundação Cultura Palmares. Sistema de Informações de

Comunidades Afro-brasileiras - SICAB 2018. Disponível em:< http://www.palmares.gov.br/> Acesso em: 05 de maio 2018.

BRASIL, Instituto Brasileiro de Colonização e Reforma Agrária. Quadro Geral do Andamento de Processos Quilombolas. INCRA, 2018. Disponível em: < http://www.incra.gov.br/sites/default/files/incra-andamentoprocessosquilombolas_quadrogeral.pdf>. Acesso realizado em 02 de maio 2018. BRASIL, Instituto Brasileiro de Geografia e Estatística. Histórico da cidade. IBGE, 2010. Disponível em:

<http://cidades.ibge.gov.br/painel/historico.php?lang=\&codmun=170220\&search=toc antins|araguatins|infograficos:-historico>. Acesso realizado em 13 de março 2017. BRASIL. Lei no 11.645, de 10 março de 2008. Altera a Lei $\mathbf{n}-9.394$, de 20 de dezembro de 1996, modificada pela Lei no 10.639, de 9 de janeiro de 2003, que estabelece as 
diretrizes e bases da educação nacional, para incluir no currículo oficial da rede de ensino a obrigatoriedade da temática "História e Cultura Afro-Brasileira e Indígena". Disponível em <http://www.planalto.gov.br/ccivil_03/_ato2007-2010/2008/lei/l11645.htm >. Acesso em 10 de setembro de 2017.

BRASIL. Lei $n^{\circ} 601$, de 18 de setembro de 1850. Dispõe sobre as terras devolutas do Império. Disponível em <http://www.planalto.gov.br/ccivil 03/Leis/L0601-1850.htm>. Acesso em: 05 de junho. 2017.

CERTIDÃO óbito de 10/04/2014 - Certidão de Óbito de Maria Francisco Barros. Acervo documental da Comunidade Ilha de São Vicente. Araguatins. TO.

CASTELLS, M. O poder da identidade. Tradução Gerhardt. K. B. 2.

ed. São Paulo: Paz e Terra, 1999.

CERTIDÃO $n^{\circ} .13$, folha $N^{\circ}, 074$, de 31/01/2018. Cartório de Pessoas Jurídicas, Títulos e Documentos, Protestos e Tabelionato $2^{2}$ Notas. Araguatins-TO. Acervo documental da Comunidade Ilha de São Vicente. Araguatins. TO.

DIÁRIO de Campo 28/11//2016. Pesquisa de Campo a Comunidade Quilombola Ilha de São Vicente. Araguatins/Tocantins, 2016. $1 \mathrm{p}$.

DIÁRIO de Campo 12/10/2017. Pesquisa de Campo a Comunidade Quilombola Ilha de São Vicente. Araguatins/Tocantins, 2017. 1 p.

DUARTE, L. G. De São Vicente a Araguatins. Cem anos de história. Marabá: J.C. Rocha Editor, 1970.

E1 - Entrevistado 1: relato [01 out. 2017, 6 p]. Comunidade Remanescente Quilombola Ilha de São Vicente, Araguatins/TO. Entrevistador: O autor. Araguatins (TO): s.e., 2017. Gravação em máquina digital 6.0 Mega Pixels.

E2 - Entrevistado 2: relato [20 out. 2017, 5 p]. Comunidade Remanescente Quilombola Ilha de São Vicente, Araguatins/TO. Entrevistador: O autor. Araguatins (TO): s.e., 2017. Gravação em máquina digital 6.0 Mega Pixels.

E3 - Entrevistado 3: relato [13 out. 2017, 4 p]. Comunidade Remanescente Quilombola

Ilha de São Vicente, Araguatins/TO. Entrevistador: O autor. Araguatins (TO): s.e., 2017. Gravação em máquina digital 6.0 Mega Pixels.

FAUSTO, B. História do Brasil. 14 ed. São Paulo: EDUSP, 2015.

FURTADO, M. B.; SUCUPIRA, R. L.; ALVES, C. B. (2014). Cultura, identidade e subjetividade quilombola: uma leitura a partir da psicologia cultural. Psicologia \& Sociedade, 26 (1), 106-115.

GUERINO, M. Mapa do Estado do Tocantins, o Município de Araguatins e a comunidade remanescente de quilombo Ilha de São Vicente em destaque. Tocantins: Do autor, 2018.

GIL, A. C. Métodos e técnicas de pesquisa social. 6 Ed. São Paulo: Atlas, 2010.

GOMES, F. dos S. Quilombos - Sonhando com a terra, construindo a cidadania. In: PINSKY, J.; Pinski , C. B. (orgs). História da cidadania. 1 ed. São Paulo, Contexto, 2003. p. 445 463.

HAESBAERT, R. O mito da desterritorialização: do "fim dos territórios" à multiterritorialidade. 3 ed. Rio de Janeiro: Bertrand Brasil, 2007.

HALBWACHS, M. A Memória Coletiva. São Paulo: Ed. Ver. dos Tribunais, 2006.

IHERING, R. V. A luta pelo direito. São Paulo: Martin Claret, 2008.

LAKATOS, E. M.; MARCONI, M. de A. Fundamentos da Metodologia científica. São Paulo: Atlas, 2003.

LARAIA, R. de B. Cultura: um conceito antropológico. 23. ed. Rio de Janeiro: Jorge Zahar, 2009. p.9-29

LOPES, R. D. Relatório antropológico de reconhecimento e delimitação do território da comunidade quilombola ilha São Vicente. Universidade Federal do Tocantins, UFT,

Palmas 2014.

MATTOSO, K. M. Q. Ser escravo no Brasil. São Paulo: Brasiliense, 1982.

MUNANGA. K.; GOMES, N. L. O negro no Brasil de hoje. São

Paulo: Global, 2006. 
O'DWYER, E. C. Os quilombos e a Pratica Profissional dos Antropologos. In: O'DWYER, E. C (org.) Quilombos: identidade étnica e territorialidade. Rio de Janeiro: editora da UFV, 2002.

O'DWYER, E. C. Terras de quilombo no Brasil: direitos territoriais em construção. In: ALMEIDA, A. W. B. de (Org.) [et al]. Cadernos de debates Nova Cartografia Social: Territórios quilombolas e conflitos. Manaus: UEA Edições, 2010. p. 42-49. OLIVEIRA, R. C. Identidade étnica e moral do reconhecimento.Os caminhos da identidade: ensaios sobre etnicidade e multiculturalismo. São Paulo: Unesp, 2006. PALACÍN, L. O século do ouro em Goiás. São Paulo: Loyola, 1994.

POUTIGNAT, P.; STREIFF-FENART, J. Teoria da etnicidade-Seguido de grupos etnicos e suas fronteiras de Fredrik Barth. São Paulo:Unesp, 1998.

REIS, J. J.; GOMES, F. dos S. (Org.). Liberdade por um fio: história dos quilombos no Brasil. São Paulo: Companhia das Letras, 1996.

REIS, J. J. "Nos Achamos em Campo a Tratar da Liberdade": a resistência negra no Brasil Oitocentista. In: MOTA, C. G. (org). Viagem Incompleta: a experiência brasileira (15002000), São Paulo: SENAC, 2000, p.242-263.

SAMPIERI, R. H. ; COLLADO, C. F.; LUCIO, P. B. Metodologia de pesquisa. 3. ed. São Paulo: McGraw-Hill, 2006.

SALLES, G. V. F. de. Economia e escravidão em Goiás colonial. Tese de doutorado. Goiânia: UFG, 1983.

SCHWARTZ, S.

Segredos internos: engenhos e escravos na Sociedade Colonial 1550-1835. São Paulo: Companhia das Letras, 2011.

TOCANTINS. Poder Judiciário - Processo no 2504/01 - Comarca de Araguatins. Cartório da Família, fls 02, 28/11/2001. Acervo documental da Comunidade Ilha de São Vicente. Araguatins. TO.

\section{NOTAS DE AUTOR}

CONTRIBUIÇÃO DE AUTORIA

Cristina de Sousa Fonseca Almeida - Concepção. Coleta de dados, análise e validação de dados, elaboração do manuscrito, participação ativa da discussão dos resultados.

Luís Fernando da Silva Laroque - Concepção. Análise e validação de dados, elaboração do manuscrito., participação ativa da discussão dos resultados, revisão e aprovação da versão final do trabalho.

\section{FINANCIAMENTO}

Não se aplica

\section{CONSENTIMENTO DE USO DE IMAGEM}

Não se aplica

\section{APROVAÇÃO DE COMITÊ DE ÉTICA EM PESQUISA \\ Não se aplica.}

\section{CONFLITO DE INTERESSES}

Não se aplica.

\section{LICENÇA DE USO}

Este artigo está licenciado sob a Licença Creative Commons CC-BY. Com essa licença você pode compartilhar, adaptar, criar para qualquer fim, desde que atribua a autoria da obra.

\section{HISTÓRICO}

Recebido em: 25-01-2019

Aprovado em: 14-06-2019 